\title{
Lo bueno y lo malo del people meter
}

\author{
¿Resuelve este sistema las necesidades de mediciones precisas y \\ confiables? ¿Qué ocurre con los reemplazos en la muestra, con los \\ rechazos a participar en ella o el comportamiento de los que aceptan? \\ ¿Se trata de sujetos tan disciplinados que aprietan el botoncito \\ correspondiente cada vez que se sientan frente al televisor?
}

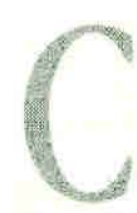

on la introducción del people meter, la televisión chilena dio el gran paso para entrar a las ligas mayores en lo que a medición de ratings y shares se refiere. Luego de cerca de dos décadas de usar un método de medición eficaz pero anticuado y lento como es el cuadernillo autoadministrado de recolección diaria, las partes involucradas- canales de televisión, avisadores y agencias de publicidad- hicieron un esfuerzo y trajeron el people meter al país.

No cabe duda de que esto representa un gran adelanto. No obstante, y sin menospreciar el

\section{GUSTAVO MARTÍNEZ JOSÉ MASOT}

\section{LAS MEDICIONES DE SINTONIAS TELEVISIVAS EN EL PASADO}

Curiosamente, no existe en Chile ningún trabajo que dé cuenta histórica de los diferentes procedimientos empleados para medir las sintonías de las audiencias televisivas.

Pero, a pesar de los vacíos bibliográficos existentes en esta materia, alguna reconstrucción limitada es posible hacer de sus principales hitos de desarrollo y cambio.

Los primeros estudios destinados a medir la sintonía de los programas de los distintos canales de televisión datan de mediados de la década de los años sesenta ${ }^{1}$.

Ellos fueron realizados por la Escuela de Administración de la Pontificia Universidad Católica de Chile y al parecer, más que medir sintonías efectivas, intentaba obtener información sobre preferencias programáticas de la población del Gran Santiago.

'Nuestra información sobre las mediciones de sintonía hechas en Chile en el pasado nos ha sido proporcionada gentilmente por el Sr. Malcolm Henderson, Gerente de Medios de $A M W$ (Azócar, Morrison y Walker). 
Una década después, en 1976, la Asociación Chilena de Agencias de Publicidad encargó a la empresa Testmerc la realización de los estudios correspondientes, los que se centraron en la medición de sintonías efectivas y hábitos televisivos y no en preferencias programáticas.

Una vez circunscritas la definición del universo y las muestras que se extraerían a la población del Gran Santiago, la recolección de datos de Testmerc se hizo por medio de un cuadernillo autoadministrado que era entregado a los miembros del hogar seleccionado aleatoriamente en la muestra.

En septiembre de 1976, la Asociación Chilena de Agencias de Publicidad (Achap) sustituyó a la empresa Testmerc por Time Media. El método de recolección de datos continuó siendo el

${ }^{2}$ No existe una expresión en lengua castellana que tenga un uso generalizado como traducción aceptada para la expresión people meter. Tal vez audienciómetro sería la palabra más adecuada. cuadernillo, pero se modificaron algunas características del registro de la información.

Time Media encargó a una persona mayor de 15 años, dentro del hogar seleccionado aleatoriamente para integrar la muestra, que anotara las exposiciones de los restantes miembros de él. A diferencia de Testmerc, que suministraba los cuadernillos y los retiraba una vez por semana, Time lo hace diariamente y chequea la información de cada persona mediante una especie de entrevista o reentrevista.

\section{EL PEOPLE METER Y LO QUE MIDE}

El people meter es un aparato de un tamaño similar a una radio de auto que mide todas las funciones que realiza un televisor, a excepción de las variaciones de volumen. En otros términos, registra cuándo un televisor se prende, se apaga, cambia de canal o cuándo se conecta a un video para ver una película ${ }^{2}$.
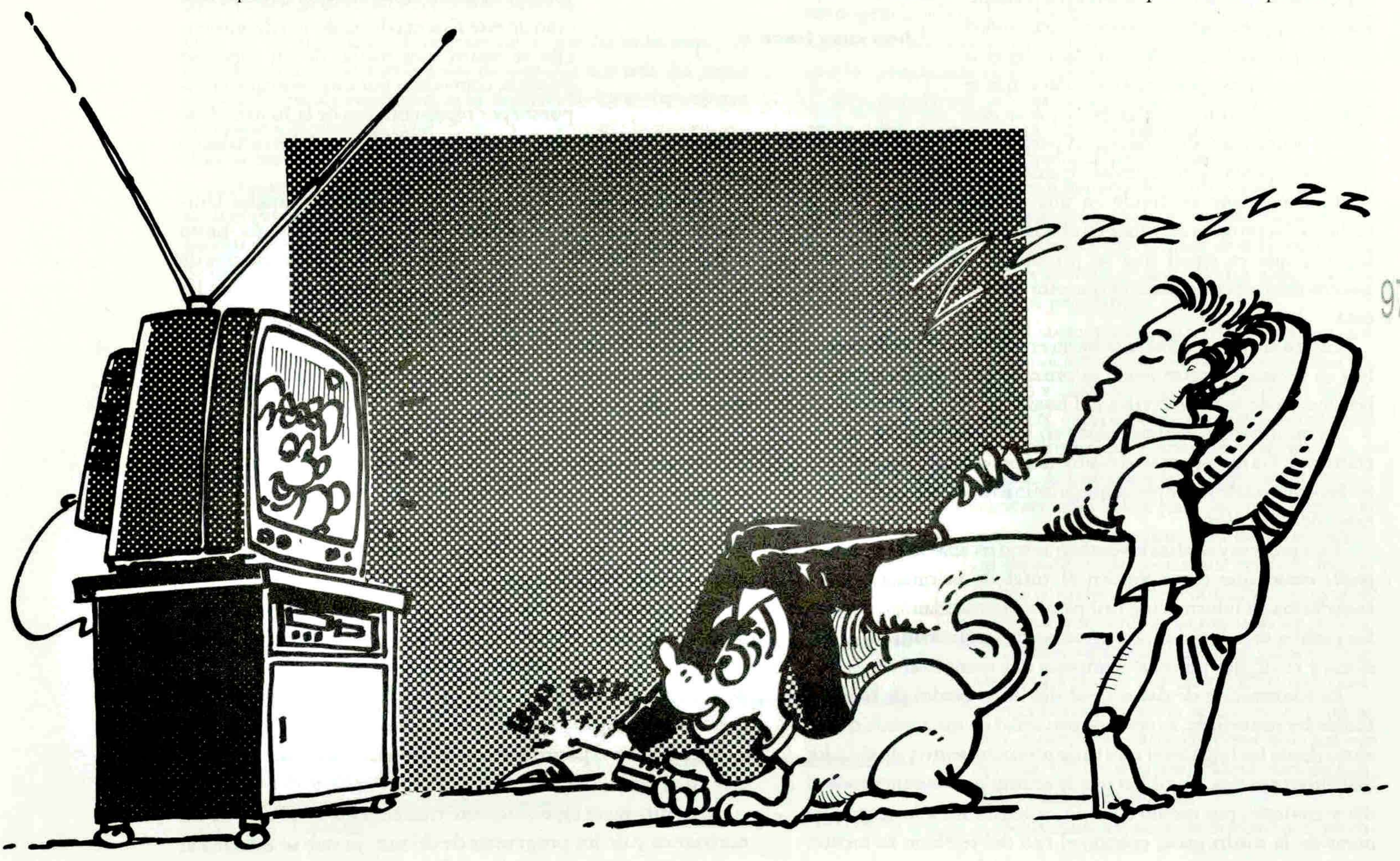

$C \cdot U \cdot A \cdot D \cdot E \cdot R \cdot N \cdot O \cdot S \quad D=E \quad I \cdot N \cdot F \cdot O \cdot R \cdot M \cdot A \cdot C \cdot I \cdot O \cdot N$ 
A lo anterior se suma que además registra quién o quiénes están viendo la televisión. Para lograr esto posee otro dispositivo, también muy pequeño con una serie de números, que corresponden a cada miembro de la familia del hogar, aunque limitado a ocho personas.

Cada vez que uno de los miembros del núcleo familiar se sienta a ver algún programa, debe pulsar el botón con el número que le fue asignado. Si el televisor se prende y nadie pulsa la señal de identificación, aparece un llamado en la pantalla del aparato, urgiendo a que quien esté de espectador oprima el botón que lo identifica. Esta operación se repite cada 15 minutos. Para mayor comodidad de las personas que proporcionan información para el estudio de sintonía, el sistema cuenta con un control remoto similar al que se usa para cambiar los canales, pero que en este caso se ocupa para identificar a las personas del hogar que están frente a la pantalla del televisor cuando está encendida.

El people meter se divide en una unidad maestra y otras esclavas. La primera se coloca en el televisor más importante de la casa, que es aquél que se presume el más visto y que generalmente corresponde al que está ubicado en el living de la casa.

Las unidades esclavas se colocan en los otros televisores que hay en la casa y transmiten la información a la unidad maestra por medio de la red eléctrica del hogar.

La información es almacenada en la unidad maestra, que la transmite vía microondas al centro del procesamiento, ubicado en las oficinas de la empresa que administra el sistema, en este caso, de Time Media.

Ésta procesa y analiza los datos que son recabados por los 300 people meters que corresponden al total de la muestra y los transforma en información útil para sus demandantes, que son los canales de televisión, las agencias de publicidad, los avisadores y cualquier persona o empresa que compre el servicio.

La transmisión de datos tiene distintos grados de rapidez. Puede ser inmediata, a través de una señal de microonda que se envía desde los hogares al centro de procesamiento y de ahí a los distintos usuarios. También puede acumularse durante todo el día y enviarse, por medio de la línea telefónica a la central en horas de la madrugada, cuando el uso del teléfono es menor.
Una tercera posibilidad es la recolección de la información del día a través de una unidad móvil. Ésta se ubica frente a los hogares que componen la muestra y por medio de ondas de radio, recaba los datos. Este procedimiento se ocupa en hogares que no poseen teléfono y se realiza en horas de la madrugada. Por último está el método más lento, en el que la información se almacena en casetes de audio, que se recogen cada cierto tiempo.

Sin duda alguna, la introducción del people meter es un adelanto tecnológico que se hacía necesario, dado que cada día se requieren mediciones más finas para determinar las magnitudes de los ratings de cada programa en los distintos horarios. La introducción de este sistema de medición de audiencias se realizó por medio de un concurso público, convocado por una comisión compuesta por representantes de la Achap, de la Asociación Nacional de Avisadores (ANDA), y de los canales de televisión existentes en el país.

Se presentaron tres concursantes. Nielsen, de Estados Unidos, asociado a Cadem de Chile; $A G B$, de Gran Bretaña, junto a Megatec; e Ibope, de Brasil, con Time Media. Los ganadores de la propuesta fueron éstos últimos, quienes comenzaron con las mediciones correspondientes a mediados del año pasado.

La introducción del people meter es un adelanto pero cabe guardar ciertas reservas respecto de su efectividad y exactitud en las mediciones que haga.

En cuanto a sus ventajas, tiene tres que representan un progreso indiscutido. Por fin se sabrá a ciencia cierta el número de televisores prendidos, apagados y los cambios de canales.

El people meter mide automáticamente estos aspectos, entregando la información al instante. Registra en forma inmediata estas tres funciones, indicando la hora exacta en las que ocurren.

Esta información entrega, por primera vez de una manera electrónicamente exacta -de no existir otros problemas metodológicos-los valores numéricos de estas tres variables, que son de inestimable importancia, ya que mide los ratings totales y la frecuencia de zapping que existe a la hora de los comerciales o de cualquier otro espacio televisivo que sea cambiado mientras esté en el aire.

Esto último es especialmente trascendente en el caso de los noticiarios y de los programas de debate, ya que se informa al 
instante el zapping cuando está en el aire algún comentarista o determinado personaje público que no concita un interés igual al programa que se está viendo. Igualmente el zapping muestra cuál es la conducta de los televidentes durante el tiempo de exhibición de las tandas comerciales.

Aun considerando estas ventajas, pecan de ingenuidad quienes creen que están resueltos nuestros problemas de poseer mediciones de sintonía científicamente precisas y metodológicamente confiables.

El empleo del people meter nos entrega mediciones electrónicamente exactas, pero esa exactitud no se extenderá a exactitud o precisión de sintonía de audiencias, que es lo que verdaderamente importa.

Veamos por qué.

\section{A. EL RECHAZO DE LOS HOGARES}

\section{SELECCIONADOS ALEATORIAMENTE}

Uno de los problemas fundamentales que ha enfrentado la introducción de las mediciones de sintonía a través del people meter en los países avanzados, es la negativa de los componentes del hogar seleccionado aleatoriamente a permitir la incorporación de los dispositivos en sus televisores.

El temor injustificado a daños materiales en sus receptores, las incomodidades correspondientes de permitir el ingreso de los instaladores, la ignorancia respecto de una hipotética falta de privacidad o de eventual espionaje hogareño y sobre todo la ausencia de incentivos que justifiquen los costos de una autorización de invasión al hogar cuyos beneficios no se advierten, son algunas de las razones justificatorias ${ }^{3}$.

Este rechazo ha sido universal; ha comprendido a Estados Unidos, los países de la Europa Occidental y también a Chile. Aunque las tasas de rechazo de la muestra ori-

${ }^{3}$ Time Media ha otorgado un ingenioso conjunto de incentivos para que los jefes de los hogares de su muestra acepten la admisión de los dispositivos del people meter. Ellos contemplan subscripciones gratuitas a revistas y periódicos de interés para los miembros del hogar y sorteos mensuales de pasajes aéreos a Buenos Aires.

Los reemplazos en una muestra probabilística con selección aleatoria de las unidades muestrales hace perder el carácter probabilístico y la transforma sólo en una muestra "disponible". ginal varían de una sociedad a otra, no cabe duda de que ellas son altas en todas partes y hace muy cuestionable que las cifras de sintonía que en definitiva entreguen los resultados de las mediciones adolezcan de sesgos cuyas direcciones y magnitudes desconocemos.

¿Por qué pensamos así?

Cuando se utilizan muestras probabilísticas -que por lo demás son las únicas que permiten estimar los parámetros de sintonía- no es posible reemplazar a las unidades seleccionadas al azar que componen la muestra. En estricto rigor estadístico, tales reemplazos no son permisibles porque no sabemos a ciencia cierta que el comportamiento de los reemplazantes será igual al de los reemplazados en las variables de interés ${ }^{4}$.

En nuestro caso, si reemplazamos un determinado hogar por otro de las mismas características socioeconómicas y zona residencial, estamos suponiendo -en forma gratuita- una alta homogeneidad en el comportamiento de las variables dependientes de un estudio de sintonía televisiva, que no son otras que los programas vistos o sintonizados.

El supuesto subyacente para justificar el reemplazo estaría en la idea de que detrás de un conjunto de atributos de caracterización social o demográfica del hogar, existe un comportamiento homogéneo en materia de conducta televisiva. En otras palabras, las personas que poseen las mismas características sociales combinadas, por ejemplo jóvenes de sexo masculino y de posición socioeconómica alta, ven los mismos programas.

Tal supuesto nos parece gratuito, ya que las asociaciones o correlaciones entre características sociales y programas vistos, de haber, son bajas, $y$ no parecen existir para muchas de las características y tipos de programas.

Así, si tomamos las estimaciones de audiencias televisivas para los programas de noticias y los asociamos con las características de background social que recogen los estudios actuales, nos encontramos con varias sorpresas que confirman nuestras sospechas.

La heterogeneidad es muy grande. Esto nos lleva a pensar que las variables que posiblemente incidan en la selección de programas específicos entre diversas alternativas

los hogares seleccionapuedan ser de otra naturaleza: sicológicas, relacionadas con gustos.

dos aleatoriamente." 


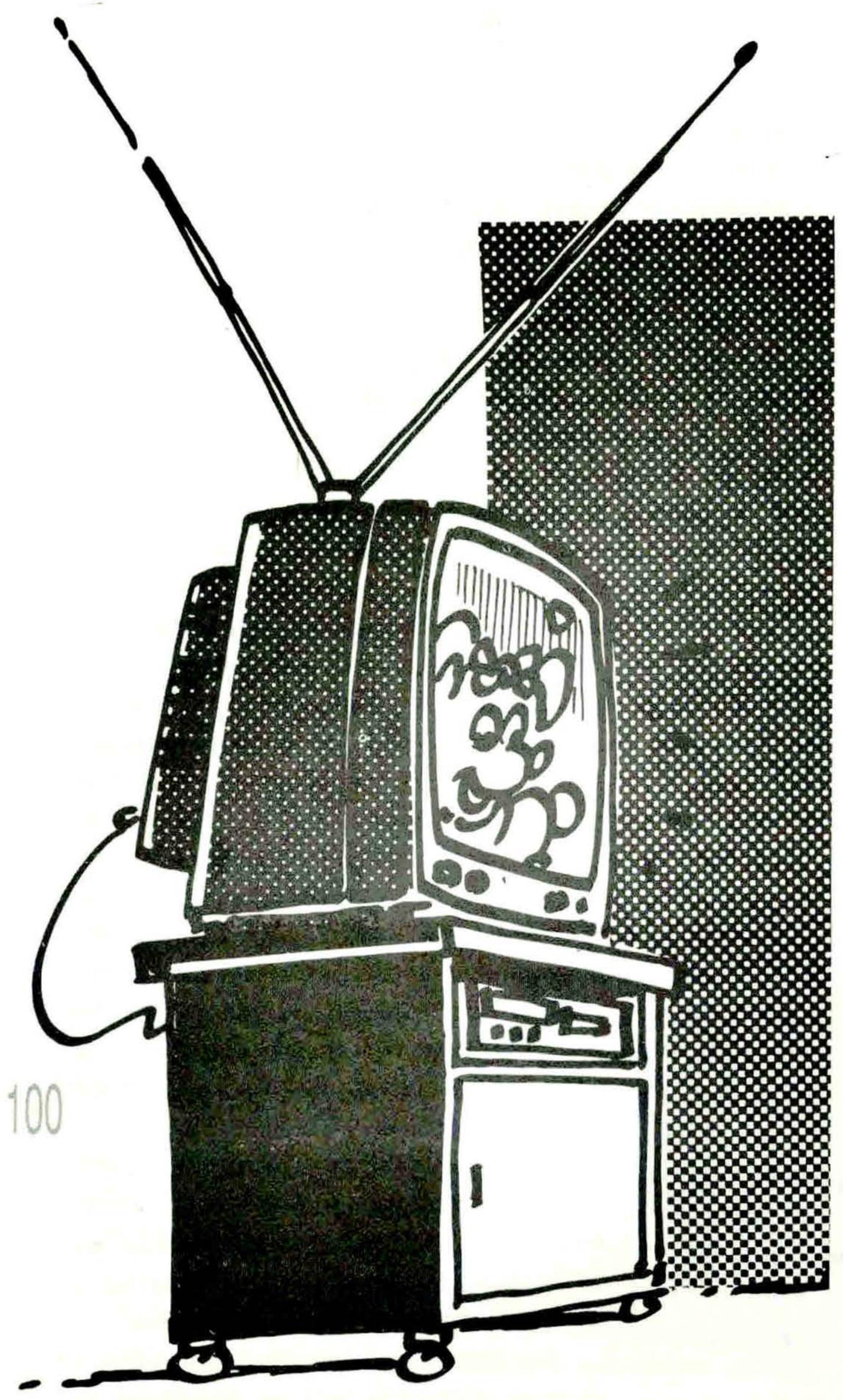

plazo de los hogares seleccionados por otros de iguales características sociales no resuelve el problema y conduce a estimaciones sesgadas.

Al margen de que estadísticamente no es posible hacer tales reemplazos, los datos empíricos no nos permitirían, haciendo «vista gorda» al rigor aplicativo de la teoría del muestreo, optar por esta selección de reemplazo.

${ }^{5}$ Véase Radio-Télévision, Suplemento de Le Monde, $\mathrm{N}^{\circ} 14.612$. Dimanche 19Lundi 20, Janvier 1992.

${ }^{6}$ Las inversiones realizadas hasta la fecha superarían los US\$500.000.
Pero, podríamos preguntarnos si hay o no otra solución...

¿Hay alguna solución que sea aceptable desde un punto de vista estadístico muestral? La respuesta no puede ser más descorazonadora: ¡no la hay!

Dentro del propio contexto de las técnicas del survey sample (encuestas por muestreo), se han buscado soluciones a este problema, sin que ellas sean satisfactorias ante las persistentes tasas de no respuesta.

Se da así la paradojal situación que siendo las técnicas de encuestas por muestreo las de más utilidad dentro de las ciencias sociales y en muchos casos, las únicas disponibles para cierto tipo de problemas de investigación, sus potencialidades para obtener conocimientos se malogran por la falta de cooperación humana.

Lo honesto sería -científicamente hablando- reconocer tales limitaciones de representatividad. Si el rechazo alcanzase a cifras del 30\%, como ocurre en Francia, sería mejor señalarle a los usuarios de la información (canales de televisión, anunciantes y agencias de publicidad) que la muestra sólo está representando al $70 \%$ de la población objeto del estudio ${ }^{5}$. Entre una información sesgada y una limitada, creemos que es preferible la segunda.

Pero si la tasa de rechazo por renuencia a permitir la incorporación de los dispositivos del people meter en la muestra original fuese muy grande y la cifra no ha sido dada a conocer, lo que tendríamos sería una información poco confiable en cuanto a la precisión de sus valores numéricos, que para efectos de ratings y shares televisivos es lo que realmente importa.

\section{B. TAMAÑos DE LA MUESTRA}

La muestra que se empleará contempla un tamaño de 300 hogares. Pero como las unidades muestrales no son hogares ni televisores, sino las personas que los habitan, de hecho la muestra alcanza a un número superior a mil personas en el Gran Santiago.

Tal tamaño no es reducido y permitirá posiblemente efectuar estimaciones paramétricas de sintonía para totales poblacionales del Gran Santiago con errores muestrales no superiores al $+3,5 \%$ para niveles de seguridad estadística de 0,95 .

El número de dispositivos de medición, que alcanza a 300, determina el número de hogares que componen la muestra, y las personas que habitan en ellos, su tamaño final. Ello se explica por el alto costo de esta tecnología y frente a la restricción de recursos parecería ser lo único razonable ${ }^{6}$.

Empero, para la estimación de sintonías no sólo interesan las 
estimaciones de totales. Las definiciones estrictas de las audiencias-objetivo de las agencias publicitarias obligan a tener -de acuerdo con las segmentaciones que se emplean para los mercados perseguidos- estimaciones para subgrupos más finos, $v r . g$. mujeres jóvenes del grupo A1, A2, B.

Ciertamente los print-outs de computación entregan tales estimaciones de audiencia (estimaciones de punto), pero ¿qué márgenes de error muestral tienen las estimaciones? Indudablemente, bastante grandes y de poco sirven al estratega de medios de las agencias publicitarias si ellas sobrepasan las cifras de $+10 \%$.

¿Cómo pueden seleccionar los estrategas de medios las mejores combinaciones de programas televisivos cuando procuran alcanzar grupos específicos de población? ¿Cómo calculan los costos por contacto? ¿Sobre la base de la estimación de punto, o al límite inferior o superior del intervalo de confianza?

Hay otro problema adicional: el de la representación geográfica de la muestra en correspondencia al universo de interés para las mediciones.

El universo de estudio es el Gran Santiago, exclusivamente; no el país. Si se tiene en cuenta que la extensión geográfica de los canales de televisión es diferente, sus audiencias reales también lo son. En Chile, la Corporación de Televisión de la Universidad Católica y Televisión Nacional tienen redes que alcanzan a todo el país, a los que ya se suma Megavisión.

Por su alta concentración poblacional, el Gran Santiago representa la mayor proporción de audiencia potencial de los canales televisivos (39\% aproximadamente).

Pero no sabemos que ocurre con las exposiciones televisivas del $60 \%$ restante de la población del país. Esto significa, para anunciantes y agencias de publicidad, la multiplicación de sus problemas de determinación realista de opciones estratégicas de empleo de canales y programas televisivos para la comunicación específica de sus comerciales y de cálculos verídicos de costos por contacto.

Pero, si no podemos tener estimaciones para el país como universo de estudio, tendremos que conformarnos con el Gran Santiago.

Sin embargo, ello no es satisfactorio y bien podrían hacerse esfuerzos en el futuro para disponer de datos provenientes de universos de estudios efectivamente nacionales. Ello iría en beneficio de los propias agencias de publicidad y canales, en la medida en que las proporciones de auditores de los programas de televisión donde se transmiten los spots de un determinado anunciante, una vez reconvertidos en totales poblacionales a nivel nacional, mostrarían audiencias muy superiores a las actuales del Gran Santiago.

Los avisadores quedarían más conformes con las estategias de medios que les hagan las agencias de publicidad. A su vez, los directores de medios podrían efectuar decisiones más eficientes para minimizar los costos por contacto y los canales no aparecerían como vendedores tan excesivamente caros de sus espacios de tiempo publicitario.

Pero, mientras no se logre emplear muestras nacionales que efectivamente representen a toda la audiencia televisiva del país, difícil será romper la cadena aparente de percepciones compartidas de canales caros, agencias caras y anunciantes inseguros de sus gastos o inversiones publicitarias.

Estas limitaciones de definición del universo de estudio y de los alcances restringidos de las cifras de audiencias no son propias del nuevo procedimiento de medición que representa el people meter. Ellas han sido permanentes en nuestro país y bien harían los propios interesados en obtener mediciones más reales en pensar en algún joint venture que permitiese ir extendiendo progresivamente las mediciones a otras regiones del país.

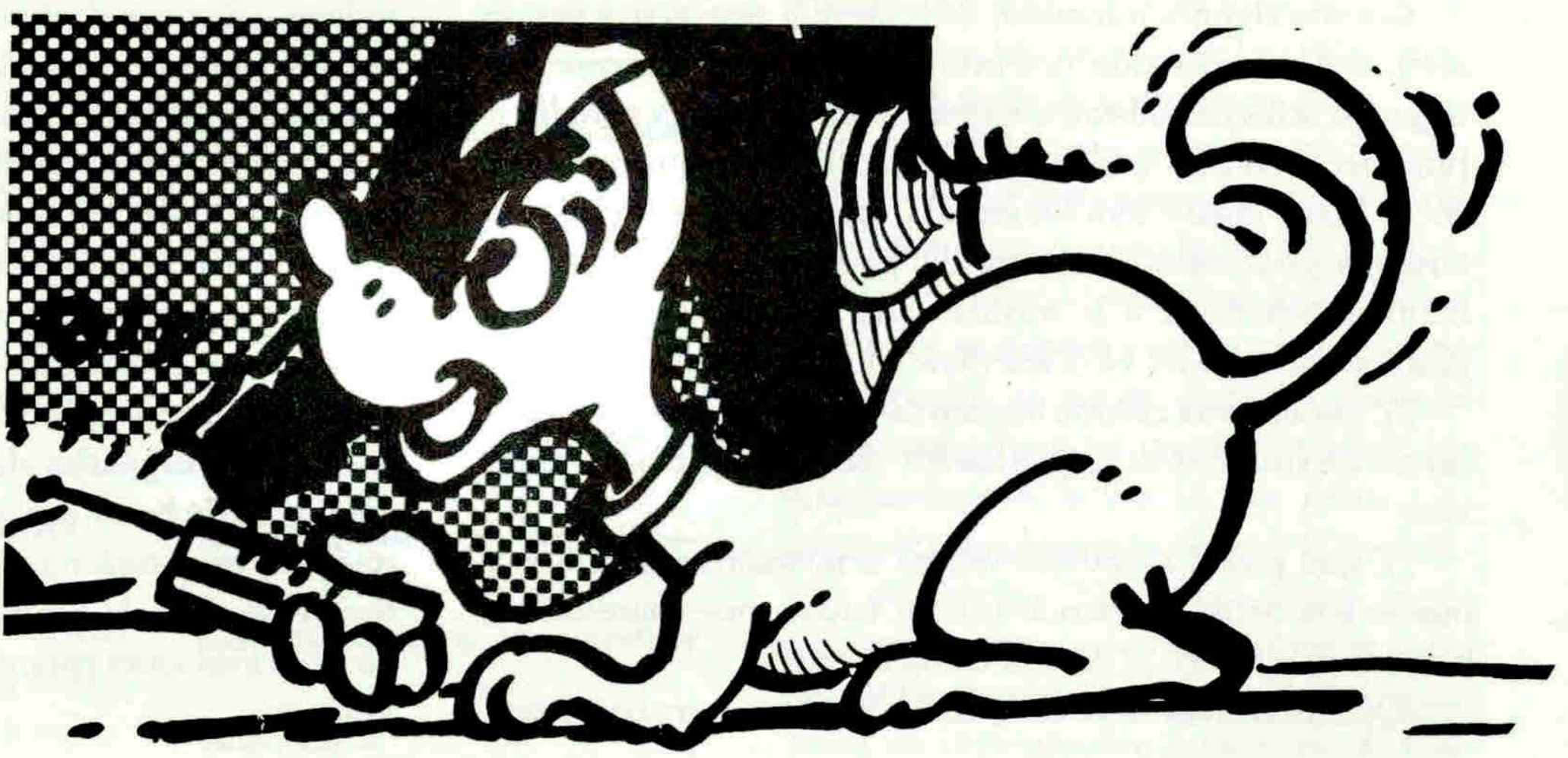


Agregando en los años venideros las regiones V y VIII se podría alcanzar la medición de un $70 \%$ del total de la población de Chile.

\section{C. DISCIPLINA DE LOS MIEMBROS DE LA MUESTRA}

El empleo del people meter supone un alto grado de cooperación de los miembros de la muestra en todas las variadas situaciones de exposición. Empero, creemos que ello no ocurrirá en todas ellas.

Cuando una persona está sola en alguna pieza de su hogar y se dispone a ver la televisión, encenderá el televisor y el people meter registrará el canal correspondiente. Igual situación ocurrirá si emplea el selector de canales y cambia esporádica o continuamente de estación. Pero todo esto ocurrirá bajo la condición de que, conjuntamente con encender

el televisor, apriete el botón que corresponda a su número en el identificador de televidentes del people meter.

Ello no representará problemas para el registro de lo que se vea en las pantallas, bajo el supuesto de que la persona recuerde efectivamente poner en funcionamiento el selector del people meter y que éste se encuentre a mano.

La situación es diferente cuando la televisión es vista en grupo, como ocurre con una familia o parte de ella reunida en algún cuarto del hogar, como el living, una pieza de estar o algún dormitorio.

Cuando algunos miembros de la familia empiezan a ver un programa de televisión determinado y progresivamente van llegando otros miembros, ¿tendrán estos últimos la autodisciplina necesaria para que en el momento mismo en que irrumpen en el lugar donde está encendido un aparato de televisión busquen presurosos el selector del people meter y contribuyan desinteresadamente a la medición de audiencias televisivas, problema que no les va ni les viene en lo personal?

¿Y qué ocurrirá cuando lleguen cansados, buscando afanosamente un sillón o sofá? ¿Qué harán? ¿Se preocuparán del people meter?

¿Y qué pasará cuando se retiren ocasionalmente para ir a buscar una bebida, vayan al baño o tengan que contestar un llamado telefónico? ¿Cómo se comportarán?

¿Qué incentivos tiene el miembro de la muestra para man- tener una conducta rigurosa de acatamiento a las instrucciones solicitadas por la empresa que hace los estudios de sintonía?

Y si bien la empresa Time Media ha sido muy ingeniosa para diseñar incentivos para posibilitar la incorporación de los dispositivos adicionados al aparato de televisión en las viviendas de la muestra, parecería que no hay «zanahorias» adecuadas para obtener la colaboración pertinente y permanente de las personas.

Los análisis pormenorizados que se hagan de las conductas televisivas que se realicen hogar por hogar y, dentro de ellos, persona por persona, podrán revelar en el futuro muchos de estos interrogantes. Pero las variaciones intrahogar o intraindividuo nos plantearán dudas respecto de si hay variaciones reales en la conducta televisiva propiamente tal o en la que registrarán en el selector del people meter.

¿Cómo determinarlo? Parece difícil saberlo. A la observación directa no podríamos recurrir por razones obvias. Del autoinforme de los miembros de la muestra tampoco podríamos esperar respuestas muy honestas. Mal que mal a ellos se les ha pedido una colaboración que han consentido y que no han cumplido si efectivamente vieron ciertos programas o partes de ellos y no han aportado la colaboración requerida, pulsando los botones del people meter cuando debían hacerlo.

¿Y si se sustituyen los hogares con miembros poco colaboradores y disciplinados por otros que lo son? No sería solución por los sesgos o eventuales sesgos estimativos de parámetros que ello conllevaría. Esos reemplazos serían equivalentes a las sustituciones de los hogares de la muestra original que rechazaron la introducción de los dispositivos de medición y registro del people meter. A las sustituciones originales de los hogares que rechazan la muestra original, agregaríamos estos nuevos reemplazos de los no colaboradores.

Rechazantes de primer momento y no colaboradores posteriores - para asignarles alguna denominación- serían sustituidos, haciendo levantar el interrogante de hasta dónde la muestra conserva un carácter probabilístico y no se transforma en una simple muestra de cuota, inhábil por sus características, para hacer estimaciones paramétricas adecuadas de proporciones de sintonía. 
Si hiciésemos la vista gorda a esto, nos surgiría otra dificultad con el reemplazo: ¿cómo podremos saber si hay colaboración o no apretando y desapretando los botones del aparato registrador del people meter?

Las variaciones interpersonales por día para cada persona tendrán que ser chequeadas por medio de entrevistas con aplicación del método del cuadernillo.

Esto aparentemente parece adecuado y nos hace recordar en una eventual solución al problema de validez que plantea el people meter.

Pero, si el procedimiento de cuadernillo fuese utilizado como criterio externo de validación del people meter en una especie de validación multi-method, entonces se estaría incurriendo en una contradicción.

Ello porque si -según sus críticos- el cuadernillo ha sido descalificado porque no registra válidamente la sintonía verdadera de los programas televisivos, entonces, ¿cómo podríamos usarlo para validar las exposiciones a programas televisivos registrados con el people meter?

Esto sería, en otras palabras, utilizar un método de medición no válido y por ende carente de confiabilidad (el método de cuadernillo) para establecer la validez o invalidez de las mediciones que proporciona el people meter.

Es obvio que esto no tiene sentido alguno. Pero, aun si pudiéramos soslayar este problema y admitiésemos que por medio de entrevistas se determinara quienes son disciplinados y colaboran con Time Media apretando y desapretando fielmente los botones del registrador de sintonía, ¿qué se puede hacer con los que no cooperan adecuadamente?

¿Podemos reemplazarlos sustituyéndolos por otras personas que tuviesen -además de las mismas características de background social-una conducta colaboracionista para el empleo del people meter?

¿Hasta dónde llegaríamos con los reemplazos para no hacer de la muestra una completamente inutilizable?

\section{D. HOGARES CON MÁS DE OCHO PERSONAS}

El selector del people meter que registra en forma individualizada las exposiciones de los miembros de un hogar sólo dispone de ocho botones numerados y la asignación de estos se hace el número uno al jefe del hogar y los siguientes, al resto de la familia en orden decreciente de edad, hasta llegar al octavo.

Esto representa una limitación tecnológica clara, que bien podría no ser grave en la medida en que en las zonas urbanas y particularmente en el Gran Santiago-predominen la familia nuclear y no la familia extensa. Ello, al menos, en clase alta, media alta y media-media. Pero en clase baja, no sólo podríamos encontrar una proporción importante de familias nucleares de más de ocho personas, de familias extensas, y, en general, de allegados.

En la medida en que estos casos pudiesen representar proporciones importantes del universo y de las muestras correspondientes, las personas que no alcancen a disponer de botones en el selector del people meter estarán subrepresentadas en las estimaciones de audiencias. Ello perjudicará los resultados de sintonía de aquellos canales que contemplen en sus programaciones televisivas programas de mayor atracción en los sectores de menores ingresos.

Si a esto agregamos que las actuales definiciones del universo de estudio excluyen a los hogares de zonas rurales y a las empleadas domésticas residentes del hogar, los canales que buscan nichos de mercado en esos sectores no se verán beneficiados por los resultados de la aplicación del people meter.

Esta situación podría afectar a canales como La Red, que ha optado por una estrategia de marketing en esos sectores.

Si la unidad muestral son los compo-
«Si la unidad muestral

son los componentes de

un hogar y el sistema tie-

ne un número limitado

de botones que se asig-

nan a cada miembro de la

familia, cabe hacer algu-

nos alcances de orden

técnico.» nentes de un hogar y el sistema tiene un número limitado de botones que se asignan a cada miembro de la familia, cabe hacer algunos alcances de orden técnico.

Por otro lado, por costumbre, los grandes eventos deportivos, musicales y artísticos que se planifican con antelación y se publicitan masivamente, como mundiales de fútbol y recitales, se tienden a ver en grupos que no corresponden al núcleo familiar. Estos se conformarían por los pares de uno de los componentes de la familia que reúne a su grupo de conocidos para ver y oír la transmisión del evento. Entonces, ¿cómo puede medirse efectiva y verazmente el rating de un programa como éste, si las unidades muestrales no corresponden a quienes efectiva-

$$
C \cdot U * A=D=E \cdot R \cdot N * O=S \quad D=E \quad I=N \cdot F=O \cdot R * M=A * C * I * O * N
$$


mente son los televidentes?

Hacemos hincapié en este último caso, debido al alto precio que alcanzan las tandas comerciales en transmisiones como éstas.

\section{EL PEOPLE METER Y LAS AGENCIAS DE PUBLICIDAD}

El establecimiento de la medición a través del people meter ha surgido esencialmente de iniciativa de los canales, especialmente de aquellos que estiman que el método del cuadernillo le es adverso porque creen, razonablemente o no, que la fragilidad de memoria de los entrevistados probabilísticos tienden a suplir el recuerdo efectivo - cuando la memoria fallapor la mención del canal de mayor prestigio, cuya imagen tiene el mayor arraigo y esté más consolidada dentro del mercado de televidentes.

Sin embargo, los efectos mayores de las posibles alteraciones de sintonía - de producirse ellas- no afectarán tanto a los principales canales de televisión.

Las posiciones relativas de "líder" y "retador del líder" no cambiarán sustancialmente. Pero los impactos consecuenciales mayores se verán en la industria publicitaria.

El people meter pondrá en tela de juicio la eficacia de las agencias de publicidad para retener la audiencia, cuando los programas sintonizados sean cortados para transmitir spots publicitarios, sobre todo en aquellas situaciones en que el telespectador es un sintonizador habitual de un programa y conoce aproximadamente la duración promedio de las tandas.

En la medida en que el people meter mida el canal sintonizado cada 30 segundos, y aproximadamente un tercio de los televisores del Gran Santiago poseen selectores a control remoto de canales, podemos saber gruesamente si el televidente huye o no de la publicidad ${ }^{\text {; }}$; si el televidente aprovecha las interrupciones de publicidad para explorar qué ocurre con los programas de otras estaciones televisivas. La presencia de al tas frecuencias de zapping son indicaciones reveladoras de la conducta del telespectador frente a la publicidad en general y a la duración de las tandas en particular.

Ciertamente se requerirá más investigación empírica respecto a la conducta del televidente ante la publicidad, la que al parecer -por información pública- no se ha realizado.

7 Datos proporcionados por el Sr. Patricio Moyano, Gerente General de Time Niedia.
Pero lo que de alguna manera se puede prever para nuestro país es que ocurra lo que ha acontecido en otros países como Estados Unidos.

Los resultados del people meter en telespectadores con aparatos con selector de canales a control remoto revelarán, a no dudarlo, el carácter de «peste negra» que la publicidad tiene para muchos televidentes.

$\mathrm{Y}$ aun cuando el telespectador no recurra al zapping, nada garantiza que esté observando los spots y prestando atención a los mensajes publicitarios. Bien podrían, al momento de exhibición de una serie de spots, bajar el volumen del televisor, iniciar una breve charla con otras personas, hojear un periódico, ir a la cocina a prepararse un café o aprovechar ese tiempo para una breve conversación telefónica.

Se necesita más investigación empírica sobre las conductas televisivas del telespectador enfrentado a la avalancha publicitaria. Y si ellas existen, que sean dadas a conocer para su discusión académica.

A nuestro entender, las mediciones del people meter en los tiempos en que se exhibe publicidad mostrarán un alto desinterés de la audiencia que puede arrancarse por medio del zapping y obligarán a ciertos cambios en la administración de la publicidad.

Es previsible pensar que el people meter obligará a utilizar spots de duración muy reducida, a la necesidad de una pluralidad variada de spots para un mismo producto o servicio, a reducir el número de avisadores por programa y a la sustitución permanente de los spots debido a su rápido desgaste.

Si bien hemos sido un tanto críticos frente a las posturas más optimistas que creen que el people meter representa una aproximación a la "panacea universal», creemos que este nuevo procedimiento de medición será beneficioso para las audiencias televisivas y estimulará creativamente, por los desafíos que implica, a la industria publicitaria chilena

Gustavo Martínez es sociólogo y cientista político, profesor de Metodología de la Investigación en la Escuela de Periodismo de la Pontificia Universidad Católica de Chile.

José Masor es periodista de la Universidad Católica de Chile y reportero del Departamento de Prensa de la Corporación de Televisión de la misma universidad. 